\title{
African American Kindergartners' Spoken Narratives: Topic Associating and Topic Centered Styles
}

\author{
SUNNY HYON
}

Elizabeth Sulzby

University of Michigan

\begin{abstract}
This article discusses narrative styles of 48 African American low-income urban kindergartners. The starting point for this study was the work of Michaels (1981, 1986, 1991) who found that during a classroom activity known as "sharing time," African American first-graders tended to produce narratives that did not cohere around single topics but around a series of loosely and offen unclearly related episodes, a style Michaels called topic associating. This was in contrast to the Caucasian firstgraders who tended to use a topic centered style. The results of the study presented here, however, reveal that of the 48 kindergarten children, 16 told topic associating stories and 28 told topic centered stories. Although storybook and fairy tale themes and structures were present across the two narrative styles, they were found most clearly in 9 of the topic centered narratives. Results show that although the patterns that Michaels reported were indeed found with these younger, urban, African American children in an uninterrupted storytelling context, these patterns were not the daminant ones. Examples of the styles are discussed, paying particular attention to the thematic and structural characteristics in the topic associating style. Issues concerning contexts for speech and literacy in the classrooms of these and other U.S. students are discussed.
\end{abstract}

In the past decade, much of the research in linguistics and language study has focused on the narrative patterns found in different communitics. Rescarchers

Earlier versions of this article were presented at the 1992 meeting of the American Educational Research Association and the 1991 meeting of the Michigan Linguistics Society. We thank the children, teachers, and administration of the School District of the City of Pontiac, MI, for welcoming us for longitudinal research. This research was funded in part by the Spencer Foundation in a grant to Elizabeth Sulzby, Combined Program in Education and Psychology, and to Marilyn Shatz, Developmental Psychology, both of the University of Michigan. We appreciate Professor John Swales of Linguistics for his comments on various drafts, as well as the editors and anonymous reviewers of Linguistics and Education. Kathryn M. Anderson-Levitt. Associate Professor of Anthropology, Department of Behavioral Sciences, University of Michigan, Dearborn, also provided suggestions in the early stages of planning. The authors discussed these and related issues about the language of African American children with Arnetha Ball, University of Michigan, Ann Arbor, and Patricia Edwards, Michigan State University. Assistance in scoring and discussing issues was provided by 
have made comparisons between the spoken narrative discourse styles of speakers from so-called "oral" and "literate" cultures. Scollon and Scollon (1981) characterized the narrative storytelling tradition of Athabaskan Indians as being "oral," in contrast with the Western "essayist prose" storytelling tradition typically used by Canadian or U.S. middle-class speakers of English. Similarly, Tannen (1982) has described differences between the "interactive," oral narrative style of Greek women and the more "content-focused," literate style of American women.

Researchers have also considered possible implications that different styles of narrating may have in educational contexts. In fact, several researchers have reported that certain narrative styles are often devalued in the classroom and treated as "less literate." Scollon and Scollon (1981) remarked that essayist-style literacy is promoted in Western schools, implicitly and explicitly, and that "the Athabaskan set of [spoken] discourse patterns are to a large extent mutually exclusive of the discourse patterns of essayist prose" (p. 53). Although Heath (1982) argued against a dichotomy of oral and literate traditions, she noted that African American working class children in a southern U.S. community used a narrative style characteristic of their home environment which led to difficulties in certain classroom literacy tasks (pp. 69-70).

In a similar vein, Michaels (1981, 1986, 1991) found that "sharing time" narratives of a group of first-grade African American children were treated as poor discourse by their teacher because they deviated from the teacher's model of literate narrative. In the classroom that Michaels studied, sharing time was an activity in which children described an object or a important past cvent in front of the class, while other class members and the teacher were allowed to ask questions or make comments. (Michaels and Cazden, 1986, also studied secondgraders, but the focus of our research is on younger children.)

Michaels (1986) observed that the Caucasian children in the class tended to produce sharing time discourse that was "tightly organized, centering on a single topic or closely related topics" (p. 102). This discourse style Michaels called

Aviva Dorfman who also collected data, along with Sulzby. George Kamberelis (now of the University of Illinois. Champaign-Urbana), Regena Fails, and Catherine Fbbs. We are indebted to the remaining members of the Computers in Early Literacy (CIEL) research team in the fall of 1989. particularly Martha Adler, Diane Holt-Reynolds (now of Michigan State University), Kathleen Hric, Mary Ann Kerttula, Laura Klenk. Moon-Ok Lee (now of Sungshin Women's University. Soeul, Korea), Kathleen Quinn-Leering, and Jodie Roth. We are also grateful to Thelma Tucker and the office staff for their assistance in transcription and analysis; and to Liliana Barro-Zecker (now of Northwestern University), Jerome Johnston (Institute for Social Research. University of Michigan). Kerry Olson, and Tamara Halle for earlier advice about the broader study. We appreciate all of the assistance we have been given, but we alone are responsible for the statements and interpretations presented in this study.

Correspondence and requests for reprints should be sent to Sunny Hyon or Elizabeth Sulzby. University of Michigan. School of Education, 610) East University, Ann Arbor, MI 48109-1259. 
"topic centered." In contrast, the African American children in her study tended to use discourse which did not cohere around a single topic but rather consisted of a series of personal anecdotes or episodes whose connection to one another "was never overtly stated but had to be inferred," a narrative style she called “topic associating” (Michaels, 1981, p. 429). Michaels (1986) argued that topic associating narratives did in fact contain structural and thematic devices but that these cues were "implicit" rather than explicit, and were thus much less apparent to the teacher. Hence, unlike the Caucasian children's topic centered narratives, the African American children's narratives were difficult for the teacher to follow because they did not adhere to the conventions of literate narrative cohesion (p. 102).

Michaels' (1981) study was concerned with the reasons why the teacher misunderstood the African American children's topic associating style and how this misunderstanding might "ultimately affect the children's progress in the acquisition of literacy skills" (p. 440). Her study did not focus on the specific frequencies of topic associating discourse among first-grade African American children, nor did it claim to generalize the discourse style tendencies observed in this classroom to other groups of African American children or to other contexts. In fact, Michaels (1981) said that her study presented only a single example of how "ethnic or subgroup differences in discourse style could lead to adverse educational outcomes" (p. 441). The frequency of topic associating discourse among African American children remains an open question, therefore. This issue of how often and in what contexts this style occurs is an important one to address because extreme generalizations drawn from Michaels' findings could create a limited notion of the discourse repertoires of African American children.

As Michaels' observation of teacher-student interactions during sharing time suggests, there is potential for negative evaluation or stigmatization when the communication style of a particular group is assessed as lacking explicit structure and cohesion. Applebee (1978) characterized children's narratives which lack connections to a central topic as being poorly developed. He used the term heap to describe a primitive form of narrative used by very young children; this type of narrative appears to have the form of free association. Another structure, which he called an "unfocused chain" is somewhat more advanced but still lacks coherence. The terms heap and unfocused chain were borrowed from Vygotsky's (1962) description of early stages of children's intellectual development. Applebee differentiated both heaps and unfocused chains from "true narratives." Lack of coherence, then, has been associated with immature speech and even with mental disorders (Rochester \& Martin, 1979). Such a stigma may also be attached to discourse labeled as "topic associating," which has been characterized as lacking the explicit style of coherence esteemed by the schools.

The labeling of African American children's narratives as emerging from an oral rather than literate tradition may itself carry a further stigma of incoherence. Gee $(1985,1991)$ has noted that the oral narrative tradition is frequently de- 
scribed in a negative light-- usually "in terms of what it lacks that the literate style has. It is inexplicit where the literate style is explicit, it is less well integrated than the literate style, less syntactically complex and so on" (Gee, 1985. p. 11). He commented that the description of African American children as topic associating "is ripe for the application of a 'deficit model': |that] these children tell these sorts of stories because they don't know any better" (Gee, 1985, p. 12). Hence, although Michaels argued that topic-associating storics do in fact demonstrate a logical and coherent system of their own, the fact that they are categorized as deviating from a literate standard may have negative associations.

In this study we examine the frequency of topic associating and topic centered discourse in another group of African American children and in a context different from the one Michaels observed. In this way, our study seeks to extend current perspectives on variation in language style across contexts. In the last 50 years the field of sociolinguistics has focused on how language may differ across contexts defined by such factors as audience, setting, and communicative task. Reid (1956) as well as Halliday, McIntosh, \& Strevens (1964) argued that speakers possess a number of different speaking styles or "registers" in their repertoires. Register studies such as that of Shatz and Gelman (1973, 1977) and Ferguson (1982) have examined how the language style used by speakers may vary according to the communicative needs of the audience (as seen in the registers such as "baby talk" and "foreigner talk") as well as by kinship relations (Haviland, 1979) and occupational settings (Prince, Frader, \& Bosk, 1982).

Other variation studies have considered the way communicative tasks may influence discourse style. In his study of low-income, African American communities in the U.S. and the West Indies. Abrahams (1970, 1972) found that in particular speech events, speakers used a style called "talking sweet" which was closer to formal, oratorical styles of English than to the everyday vernacular. Labov. Cohen. Robins, and Lewis (1968) also observed that within certain speaking tasks, African American adolescent street gangs in New York City used a markedly formal discourse style called "rifting" characterized by "an elevated. high-flown delivery which incorporates a great many learned, Latinate words" (p. 136). Communicative task context has been shown to influence the language forms used by nonnative speakers of English as well (Selinker \& Douglas, 1989).

Perhaps more directly related to the concerns of this study, research on variation in children's narratives has found that children may use very different narrative registers, or styles, depending on the task context. Hicks (1991) observed that first-grade children demonstrated different discourse patterns in narrating a single film depending on the task prompt. In her study, the children were asked to narrate a film in three different ways: as a simultaneous event cast, as a factual news report, and as a storybook narrative. She noted that in each of these three tasks, the children's narratives reflected differences in perspective, event sequencing and amount of evaluative commentary provided. Similarly, Hudson and Shapiro (1991) have reported that in three different tasks, young children 
produced three types of narratives: scripts (accounts of habitually occurring event sequences), past tense personal narratives, and original fictional stories.

Sulzby (1985) contrasted kindergartners' stories when they were asked to tell a story, dictate a story, or write a story. In each case, the tasks were presented as something that a person does as preparation for writing. Whereas she found that children shifted styles in terms of intonation and pausing in these conditions, she also noted that stories in all three conditions were much shorter than those reported in studies eliciting uninterrupted storytelling in a context not connected with literacy (Menig-Peterson \& McCabe, 1978; Peterson \& McCabe, 1983). She speculated that the effect of tying storytelling to storywriting preparation had created a literate bias in these children from an upper-middle-class suburban school. With children this age in classrooms that do not typically encourage children's emergent writing, written stories tend to be much shorter than orally told stories (Sulzby, 1985), but in this case the orally told stories were also much shorter than expected.

This study explores narrative styles used by a group of low-income, African American kindergarten children in a context defined by a particular communicative situation and narrative task. Although Michaels (1981, 1986, 1991) observed a tendency towards a topic associating style among a group of African American children within the context of sharing time in which other speakers were allowed to interrupt, ask questions, or redirect the storyteller, it is not clear whether this same pattern would be found in a different group of children and in a different context. It may be that a group of younger African American children will display an equally strong or stronger tendency towards a topic associating style in a different narrative context, uninterrupted face-to-face storytelling. On the other hand, they may show a different tendency. This article reports on the frequency and characteristics of topic centered and topic associating styles among a group of African American, urban kindergartners and discusses possible influences of context on the children's narrative styles. Before we proceed, however, we offer some terminological clarification that situates our study.

\section{DISCOURSE TERMINOLOGY}

The terms genre, register, and style are often confused in discussions about discourse. We would like to clarify how we are using these terms to refer to the children's topic associating and topic centered narratives. Researchers have defined narrative in a variety of ways, making it difficult to achieve consensus on the exact nature of this discourse. Labov and Waletzky's seminal definition (1967) involves a temporal sequence of past events including an abstract, orientation, complicating action, evaluation, resolution, and coda. Others have proposed episodic schemas of narrative as alternatives or additions to Labov and Waletsky's "high point analysis" (Peterson \& McCabe, 1983; Stein \& Glenn, 1979). Also, where Labov and Waletzky have stipulated that narrative discourse 
must be grounded in the past, others have included habitual discourse in their definition of narrative (Hudson \& Shapiro, 1991). Gee (1991) argued that the unmarked, fundamental narratives are those in which "juxtaposition and relations in an imaginary space is much more important than [temporall order itself" (p. 8).

Considering these varied criteria, we are not treating "narrative" as a genre in itself. Swales (1990) has proposed that a genre must have a clear set of communicative purposes with a recognizable schematic structure. He argues that narrative does not constitute a genre because it reflects a variety of different purposes as well as correspondingly different structures, as seen in news stories. scientific reports, and jokes. However, Swales refers to narrative as a "pre-genre" and suggests that it does reflect some recognizable properties (p. 61). Indeed, the various narrative definitions such as those of Labov and Waletzky (1967), Gee (1991). Hudson and Shapiro (1991), and Peterson and McCabe (1983), seem to share a notion of narrative as a description of persons, scenes or events (whether temporally ordered, past, habitual, or future) for some meaningful effect, or as Gee (1991) suggests, "a perspective that human beings take on the way in which certain themes fall into a satisfying pattern" (p.13). Thus, as we refer to the children's "narratives" in this study, we are not suggesting that such narratives reflect a "genre" sharing the same purpose and structure as other narratives, but rather that they fall into the more flexible category of pre-genre.

The specific types of narratives that the children tell, however, may represent more recognizable categories. Hicks (1991) has described the three types of narratives in her study as different genres because they reflect different purposes and structures. Similarly, topic centered and topic associating narratives have been distinguished by a number of structural and stylistic features (Gee, 1985. 1986; Michaels, 1981, 1986, 1991). However. despite the distinctive qualities of these two narrative types, it is not clear that the two represent different communicative purposes and thus two separate genres. Topic associating narratives, for instance, might appear in a variety of contexts with very different purposes, such as a conversation between peers, a classroom sharing time presentation, or a written composition. The same could be said of topic centered narratives. Michacls (1986) has sometimes referred to topic centered and topic associating discourse as two narrative "styles." Indeed, the terms register and style have been used, often interchangeably, to capture structural and linguistic variation within narrative discourse (Christie, 1991; Tannen, 1982). Like Michaels, therefore, we will also refer to topic associating and topic centered as different styles of narrative. Finally, in this study. we are using the terms story and narrative interchangeably to refer to the children's discourse. Although some researchers have restricted story to fictional narrative accounts based on the structure of storybooks (Hudson \& Shapiro, 1991), children's and adult's narratives, both fictional and personal experience, have often been described according to "story grammars" (McCabe, Capron, \& Petcrson 1991; Peterson \& McCabe. 1983). 
Tannen (1982) has also treated adult narratives as stories. Moreover, as discussed in the method section, the narratives in this study were produced in response to a request to tell a story and thus, the term story serves to connect the narratives with the elicitation context.

\section{METHOD}

\section{Subjects}

Data for this study come from the outset of a longitudinal study of emergent literacy in Pontiac, Michigan. Pontiac is a small city in the greater metropolitan area of Detroit; it fits the description of "rust belt" in that the automobile industry has continually closed factories and laid off workers. Over $95 \%$ of the children in the district are on reduced-price or free lunch.

In all, the children and teachers in eight kindergarten classrooms across five schools took part in the larger study (Sulzby, 1990; Sulzby, Branz, \& Buhle, 1993; Sulzby \& Kamberelis, 1990). For this study, we used 48 narratives elicited from kindergartners in four classrooms containing the highest proportion of African American children. The storytelling data were collected at the beginning of the first year of what has become a 4-year study. After that time the study focused on literacy development.

At the beginning of this year, teachers and administration in the district were exploring a common philosophical stance for kindergarten through second grade, turning from a heavy emphasis upon skills and moving toward a child-centered philosophy incorporating practices that included a developmental approach to literacy that encouraged child initiation and activity. Our observations showed that, at this time, none of the four teachers regularly included children in storybook reading and only two, one at each school, read to the children regularly. At the time the data were collected, we were just starting to ask teachers to begin to read to children regularly and repeatedly from children's literature and immediately after this data collection, we began to help teachers to encourage children's writing.

In the four classrooms, $81 \%$ of the children (64 of the 79 children) who were enrolled and present for the storytelling elicitations were African American. Because the main purpose of the study was to assess the frequency of topic associating narratives among African American kindergartners, only the African American children's narratives were used. (The question of how the African American narratives compared with those of other ethnicities in the classroom will be reserved for another study.) Of the 64 African American children in the classrooms, 7 refused to tell a story even after several prompts. Two other stories were inaudible and 3 were on missing tapes. Also, 4 stories were omitted, one that was less than 4 clauses long and 3 that were produced as songs. This left a total of 48 narratives for the study. All children are referred to by pseudonyms. 


\section{Elicitation}

The storytelling task was conducted in a one to one fashion between the child and a member of the research team. We took every effort to help the children become familiar with us as part of the classroom community but did not identify ourselves as literacy researchers until after the storytelling session. We prepared by studying interactive patterns likely to elicit African American children's speech. and, in particular, storytelling. Researchers were familiarized with Michaels' and Sulzby's earlier work and were given training in the particular elicitation procedures for this study. Researchers were chosen for their interest in, and familiarity with, African American children, if they themselves were not African American. The research team included two African American researchers, two senior researchers who had had extensive experience working with African American children in various settings, and others with differing degrees of familiarity with these and other groups of low-income and/or minority children. The longitudinal study in Pontiac immediately followed a 1-year study in four classrooms in Ann Arbor, Michigan, in which African American children were focal children but comprised no more than $22 \%$ of the classroom populations.

Each adult had previously visited the children's classroom for 3 to 5 days as observers. As we left the classroom, we reintroduced ourselves and told the children that we would like them to help us, if they were willing, and that we would bring them back to "Ms. X's room" when we were finished. We kept up conversation, encouraging children to talk as much as possible on our way to the rooms for storytelling. Care was taken in furniture arrangement and nonverbal behaviors. Two chairs had been prearranged to face each other. The adult helped each child to sit in one chair and then sat, without anything in his or her hands, in the second chair facing the child. In a conversational manner, the adult introduced the child to the tape recorder as a way of helping the adult remember "what we say to each other." We promised to let the child hear the recording at the end of the session.

The adult used a simple invitation to ask the child to tell a story. The adult then waited with an attentive look, focusing at or near the child's face to begin with, but moving quickly off to the side, depending upon the child's perceived comfort with direct gaze. The child was asked to tell a story about a topic of his or her choice. with a general framework of its being a previous experience. Specifically, the interviewer's prompt to the child was "Today, (child's name). I want you to tell me a story. The story can be about something fun or exciting that vou've done or anvthing else vou wam to tell about." Other than that. as litte input as possible was given by the interviewer during the narrative production. These techniques, used after piloting, indicated that children were more responsive if adults acted expectant but did not talk or query the child much. Occasionally, if the child had a difficult time starting, the interviewer offered story topic suggestions like "tell me a story about something fun you did with your family or about all the things you do when you play on the playground." In all cases, the 
adult waited until the child clearly signaled that he or she was finished with the story.

As part of the Sulzby general training, researchers were directed not to interrupt the child during the story nor assume that a child had finished the story until the child had signaled completion. For this study, these directions were expanded to pay particular attention to the characteristics of storytelling that Michaels had described, including prosodic cues about clause and story completion. Sometimes, waiting for the child to signal completion resulted in a long pause during which the adult looked at the child directly and questioningly, and then, after a while, said, "Hmm?" and finally said, "Are you finished?" No child was cut off because of time constraints, although, in one case, the adult was ready to stop the child to prepare for the end of the school day when the child suddenly brought the very long story to a close and said, "I'm done." The researcher (E. Sulzby) felt that the story seemed to have been abruptly terminated, but the audio tape recording and its transcript showed that the child had indeed brought the topic associating story to a close.

\section{Analysis}

Each of the kindergartners' transcribed narratives were categorized into one of the two narrative types described by Michaels (1981, 1986, 1991). Details of the actual classification process follow a presentation of Michaels' category criteria. In Michaels' (1981) study, the categories topic centered and topic associating were characterized by a number of features which have been summarized in Table 1. We should note that later, Michaels and Cazden (1986) changed Michaels' original category name "topic associating" to "episodic." However, because they did not change their description of this category notably, we have chosen to keep the term topic associating for this analysis.

Michaels (1981) described topic centered narratives as being tightly organized around a single object or event. Temporal and locative information remained consistent throughout topic centered narratives, and this consistency helped to

TABIE 1

Narrative Style Category Definitions

Topic Centered

1. Narralive is organized around a single object or event.

2. Temporal and locational grounding and key characters remain consistent.

3. Key lexical items are repeated.

4. Narrative follows a linear pattern of organization-with a clear beginning, middle, and end.
Topic Associating

1. Narrative is organized around a series of implicitly linked anecdotes or episodes.

2. Temporal and locational grounding and key characters frequently shift.

3. Narrative does not adhere to a linear pattern of organization but may reflect other structural and thematic patterns. 
make them appear to have a singular thematic focus. Such narratives achieved thematic cohesion through repetition of key lexical items which were often related to familiar cultural routines such as sports or major holidays (Michaels, 1981, p. 428). Moreover, Michaels and Cazden (1986) noted that the structure of the topic centered narratives demonstrated a linear pattern of organization, having "a marked beginning, middle and end" (p. 136) and followed a sequence of events leading to some resolution. In some examples, they noted that the stories followed a standard narrative format with an orientation, complicating action, and resolution, though not all the topic centered examples contained these elements (Michacls \& Cazden, 1986, pp. 142-143).

In contrast, topic associating narratives were characterized, not by a linear development around a single topic, but by a series of unclearly related anecdotes or episodes. Unlike topic centered narratives, topic associating narratives were marked by frequent shifts in time, location, and key characters. Because the connections between episodes were never explicitly stated, topic associating narratives appeared on the surface to be without linear structure or thematic focus, to have "no beginning, middle or end and thus, no point at all" ( 1981. p. 429). However, Michaels emphasized that these narratives were not without thematic cohesion. She argued that the " 'topic associating' style . . consists of a series of segments or episodes which are implicitly linked in highlighting some person or theme" (1986, p. 103). Michaels looked mainly at prosodic cues as evidence for thematic ties and left the question of other coherence strategies relatively open. Since Michaels' first article, however, Gee $(1985,1986,1991)$ has analyzed topic associating narratives from Michaels' study more thoroughly for thematic devices and coherence strategies. Gee has observed that topic associating narratives often use structural frameworks found in literature, such as stanzas, which reflect intricate internal patterning. He has also noted that topic associating narratives achieve coherence through the repetition of themes and contrasts across various episodes.

In categorizing the Pontiac narratives, we attempted to apply Michaels' and Gee's criteria as closely as possible, paying particular attention to lexical repetition, temporal and locational grounding, thematic shifts, linear organization, and stanza structure. Perhaps more than Michaels, we extended the notion of a "linear progression of information" to include adherence to a standard narrative canon of the kind proposed by Labov and Waletzky (1967). Also, one aspect of Michaels' classification system that was not included was her analysis of prosodics in topic centered and topic associating narratives. Although Michaels used prosodic information to distinguish between the two narrative types and to show how topic associating prosodic cues were misinterpreted by the teacher, these cues were not considered essential for placing the narratives into one of the two categories for the purposes of this study.

The process of placing the stories into the two categories involved the first author listening to each story on tape four to seven times, taking notes on the presence of features relevant to the topic centered or topic associating categories, 
and transcribing each story. The second author had collected part of the data and later listened to problematic or exemplary tapes. All the transcripts were checked by a minimum of four transcribers. The narratives were placed into one of the two categories by two raters (the first author and another researcher working on a related paper). The inter-rater reliability was $87.5 \%$. Of the 6 children the raters disagreed on $(12.5 \%)$, easy agreement was reached in 3 of the cases after short discussion. The other 3 disagreements were mainly due to different opinions about whether a child's reference to a new character signaled an abrupt topic shift. In calculating the frequency of the narrative styles, the disagreements were resolved by using the first rater's judgments, in consultation with the second author. Examples of the two narrative categories are discussed in the next section.

\section{RESULTS AND DISCUSSION}

First, we would like to return to the starting point of our analysis, the fact that of 64 low-income, African American kindergartners, 48 told stories long enough to be analyzed by Michaels' scheme. In fact, only 7 refused to tell a story. This is particularly impressive when compared with our field notes from the four classrooms. In these classrooms, children were not observed to have opportunities for extended oral discourse except on the playground. Yet, these children appeared to have storytelling readily available in their linguistic repertoires.

The stories told by these 48 children included both topic centered and topic associating narratives. Before we discuss the frequency of the two narrative styles, we present and discuss representative narratives from the topic centered and topic associating categories, respectively. A few notes about the transcripts: each line represents a new clause; " $X$ " stands for inaudible, with each " $X$ " equivalent to one syllable. For ease of reading, false starts and hesitations have been omitted.

\section{Representative Narratives}

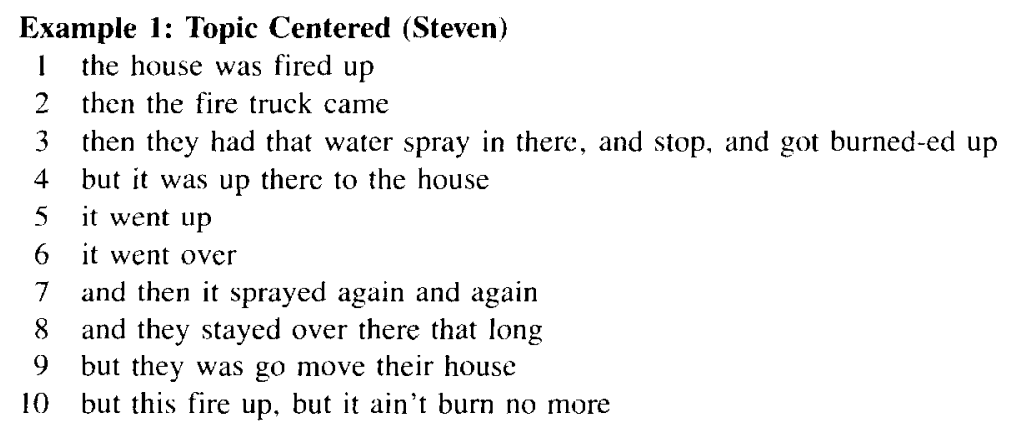

Steven's narrative, categorized as topic centered, is a story about a fire being extinguished. Notice that nearly every clause in Steven's narrative is related to a 
single topic of firefighting: the arrival of the fire truck (Line 2), the spraying of the firc hose (Lines 3, 4-8), and finally the extinguishing of the fire (Line 10). This singularity of theme gives Steven's narrative the appearance of topic centeredness. Moreover, the narrative follows a linear structuring of events characteristic of a topic centered style, with a complicating action, or "high point," (the house on fire/firefighting) and a resolution (the fire being extinguished).

Thematic cohesion in Steven's narrative is also wrought by the repetition of key lexical items. In this narrative. we see the repetition of "water spray/sprayed" (Lines 3, 7), "fïre" (Lines 1, 2, 10), and "burned-ed/burn" (Lines $3,10)$. Moreover, these words relate to a salient concept in our cultural experience-firemen putting out a fire--which, according to Michaels, also lends topical cohesion to a story (Michaels, 1981, p. 428). Thus, the singularity of theme, linear organization, and lexical repetition give Steven's story its topic centered style.

\section{Example 2: Topic Associating (Spencer)}

1 Yesterday I went down home

2 and I was slecp

3 and I ask my mamma

4 I was telling her a story about Goldilocks

5 and she say, "mm mm"

6 she didn't want me to tell her no Goldilocks story

7 I was about to say it all to my own self

8 and now yesterday it was dark

9 and Lynn went over there a long time

10 and Lynn went over Gramma's

11 and she came

12 she was about to go back over my house

13 and she fell down on the porch

14 and she had one of those pills

15 and one of those bumps was right on there

16 and the skin peeled off too

17 and now she laid in the bed

18 my mamma had to get her some ice

19 and I went over Gramma's to spend the night

20 and I had to go to school

21 and 1 got a little baby cat and a big eat

22 the baby cat is gone somewhere

23 I need to go find her

24 but the big cat just stay over my house

25 and $I$ just pet him

26 the little baby don't bite

27 and the big one don 't bite me

28 and yesterday $I$ went to the pizza roller skate party

29 and the Little Caesar's $X$

30 and I was at home 
31 I had my birthday

32 and I could read all my books

33 and I do my homework

34 and I got this

35 play with Randall

36 and I play with my toys

37 and I could read my book all by myself

38 'cause my mamma teach me how to read the jungle book

39 and I just read it

40 my mamma said "take the cornbread to over and over Gramma"s house"

41 and I asked Rudy, I said, "you want some um"

42 I forgot the dinner

43 I said, "you want some um"

44 I said, "Rudy and Gramma,"

45 and she said "huh?"

46 "you want some cornbread and stringbeans?"

47 and they said, "uh uh"

48 but you talk to gramma

49 and gramma just say

50 they saying, they say "none of your beezwax"

51 and Rudy call me knucklehead

52 and John boy call me peanut

53 and I call John boy motor mouth

54 he call me everyday that, motor mouth

55 when he come over my house, motor mouth

56 what you do with that? [Spencer notes the microphone]

Adult: That's part of the microphone. That hooks up into this thing that records your voice. Anything else with your story?

57 Oh, so you go talk on the microphone?

Adult: Yeah, exactly. And I'll play it later and you can hear yourself.

58 and that what they be doing on Ochra [probably referring to Oprah Winfrey show]

59 the Ochra just got microphone, that's all

60 and the other people don't got microphone

61 they just sit down

62 and Ochra just get the microphone to them

63 and they talk on there

64 and you look at Ochra? [to interviewer]

Adult: Do I watch it? Yeah, I do, I like it

65 You got a little boy at home too?

Adult: $\mathrm{mm} \mathrm{mm}$, no

66 oh, but my mamma work at Target

67 and she hate working there too 
68 and when my mama was sleeping

69 I said, "Once upon a time, there was three Goldilocks"

70 and she said," $\mathrm{mm} \mathrm{mm"}$

71 and she was sleep

72 and next day she had to go to work

73 and now Rudy had to come over my house and come pick me up

74 so I could go to bed over at gramma's

75 'cause Lynn sleep

76 and 1 could do my honework, you wanna see?

Adult: Do I wanna see what?

77 doing my homework

Adult: How about later? Are you finished telling your story, Spencer? No? OK, what else?

78 and when I was sleep

79 I was dreaming something

80 like I was having a

81 it was bad too

82 like I was inside a hall

83 I was digging

84 and I thought I was dreaming about big ol'

85 I was dreaming about three little pigs

86 and I was a pig

87 and a wolf came on the roof

88 and he jumped inside the bowl of water

89 I was so happy

90) cause I'm scared of wolf

91 I went to Sondria party

92 I was Pee Wee Herman with my costume on

93 and I saw Freddy Kruger there and a jack a ler too and a werewolf and a batman, and a bat, and a witchy witch

94 I went to K-mart and I saw Freddy Kruger and glove and inja ninja turtles costumes and Donald Duck, Big Bird and oh and Grovert [sic]

Adult: Are you finished with your story Spencer? no?

95 I was. how old $X X$ was?

96 and I was um seven years old

97 I think I was not turn four

98 and 1 turn five

99 I think I was seven

100 and I turned four

101 me and Louis was four

102 and I turned five

103 and I was first time I was in preschool

104 and 1 got out of there 
105 and I came to kindergarten

106 and my mamma hate working too

107 and I hate just going to school

108 my mama be crying

109 and I cry

110 and Louis be hitting people

111 I just hit him back

112 just like Tanya told me yesterday

113 if Louis hit you, hit him back

114 that's what Tanya told me to do back to him

115 and I hit him back everyday

116 what I go when Tanya's in

117 that's the day he hit me

118 and I told Tanya

119 what I was over Tanya's

120 Louis has all the vitamins

121 and Tanya told me to hit him back

122 and I hit him back

123 and Louis be

124 and yesterday he hit me

125 and Tanya said, "why you keep hitting him?"

126 and I hit him threc times

127 I hit him one two three

128 and now he keep hitting me

129 and Tanya was downstairs

130 she came upstairs

131 and now she said

132 I just hit him

133 I hit him right there on the face

134 and she hit Louis

135 and he cry hard, loud too, just like [squeak]

136 all loud, just like he was screaming loud

137 cause Sheri told me if you scream loud

138 the police take you inside jail

139 and so I see the jail

140 and you can't get out

141 and 1 got a puzzle book for $A B C$ 's puzzles

[Child is shifting in the chair]

Adult: Why don't you bring your legs up, OK? Are you finished with your story Spencer?

142 and I was every time I be dreaming something like monsters

143 when I go to bed

144 and I dream

145 I just like go to bed

146 and I wake up 
147 and I didn't go to bed

148 and I keep doing it

149 and I dream something

150 and I now I'm trying to think what

151 yesterday 1 was sleep

152 and I dream a monster

153 and I was scared

154 and I woked up

155 and I was still keeping my eyes open

156 I was thinking what I want to dream

157 just like I was dreaming about wolfs

158 and I'm going to be Freddy Kruger

159 and Randall gonna be batman

160 and Decolby gonna be a dracula for Halloween

161 What are you going to do with that? [Spencer notices paper on the table]

Adult: With what?

162 With this papers.

Adult: Well, I'll tell you that in a minute. When you're finished telling your story, l'll tell you what you're going to do with that. Are you finished telling your story? You've finished telling your story? Whoa, that's a great story Spencer.

Spencer's narrative is 160 clauses long. Indeed, such lengthiness may characterize the topic associating style. None of the topic centered narratives were anywhere near this long. The longest topic centered narrative was 35 clauses. Michaels' (1986) study also suggested that the African American first-graders' topic associating narratives tended to give the impression of being lengthy. She noted that the children"s "[sharing] turns were often cut short by the teacher who jokingly referred to them as "filibusters" on occasion" (p. 102). However, it is difficult to assess the actual length of the topic associating stories in Michaels' classroom since they were so often cut off in midstream by the teacher.

Spencer's story illustrates a topic associating style in that it involves not just a single, linearly developed topic but a number of different anecdotes which frequently shift in time trame, location and characters. Spencer began his long narrative by telling about how he tried to tell his mom the Goldilocks story one night (Lines 1-7). Then, in Line 8, he shifted to another anecdote about a new character Lynn (perhaps a close relative), who went over to Gramma's house and fell down on the porch (Lines 9-18). This anecdote is perhaps connected temporally to the Goldilocks episode since they are both marked as occurring "yesterday" (Lines 1, 8). However, the events do not follow a linear sequence, since the first anecdote appears to occur at bedtime ("I was sleep" Line 2) and the second earlier in the evening. The relationship between the two episodes is thus not achieved in a linear, topic centered fashion. There is no connecting phrase, such 
as "before I went to bed, Lynn. . . ," which links the two anecdotes. Michaels (1981) noted that this "absence of lexicalized connectives" is characteristic of a topic associating style (p. 429).

In Line 21 , there is a definite shift in theme and time frame as Spencer switched to talking about his cats (Lines $21-27$ ). Here his storytelling is also no longer grounded in the past but in the habitual present. He described the present states and attributes of his cats: "The baby cat is gone somewhere", "the little baby don't bite."

After the cat sequence, Spencer shifted back again to the past with "yesterday I went to the roller skate party" (Line 28). Here, Spencer may have been using "yesterday" as a general past event marker, not specifically referring to a particular day. Peterson (1990) reported that young children often use "yesterday" in this way. In any case, on the surface the party does not appear to be explicitly related to the "Goldilocks" or "Lynn" episodes (which were also said to occur "yesterday"), or to the "cats" anecdote.

Lines 30 through 39 switch settings again from the roller skating party to his home. Spencer did seem to continue the "party theme" in Line 31 by saying "I had my birthday" (presumably in his home) but the relationship between this and the other party is not immediately apparent; they appear to have occurred at two different places and at two different times, and are only linked loosely to a general party theme. Moreover, the connection to the party theme is not continued for long; Lines 30 through 38 focus on the activities Spencer does in his home, which besides the party include reading books, doing homework, and playing with toys.

In Line 40, there is another quick shift in setting and focus from Spencer's personal activities at home to an interaction with Rudy and Gramma about dinner at Gramma's house. The rest of Spencer's narrative contains a number of other episodes which shift in time, location and key characters. They include another bedtime interaction with his mother about Goldilocks (Lines 66-72); a scene with Rudy and Lynn and Gramma (Lines 73-75); a bad dream sequence (Lines 78-90); a scene at Sondria's party where he saw Halloween costumes (Lines 9193); a sequence about fighting involving Louis, Tanya, Sheri, and the police (Lines 110-139); and another bedtime dream episode (Lines 142-157).

All of these frequent thematic and temporal shifts in Spencer's story give it its topic associating appearance. However, as may have already become apparent, although Spencer's narrative involves a number of different episodes, it does not lack structure and thematic cohesion. Indeed, Spencer's narrative reflects a number of the thematic and structural devices which Gee $(1985,1986,1991)$ has found to be characteristic of topic associating discourse. In two topic associating narratives told by a girl in Michaels' study, Gee has observed that topic associating narratives are often divided into different stanzas, reminiscent of the stanzas found in poetry and oral literature. Gee (1986) has argued that the stanzas in topic associating narratives consist of a "series of lines [often 4] that have parallel 
structure and match each other either in content or topic" (p. 396). In Spencer's narrative, we can also see evidence of stanza structures which display neat internal "patterning" (Gee, 1986, p. 396). The opening four lines of his story, for example, appear to form a stanza as they each have the structure of "I + verb phrase." They also display what Gee (1986) calls an "aabb" structure. The first two lines both describe Spencer's state of being: "I went down home" and "I was sleep," whereas the second two lines involve Spencer asking/telling his mother about the Goldilocks story. Similarly, Lines 5 through 7 form a stanza which focuses on the result of Spencer trying to tell his mom the Goldilocks story. Here, Lines 5 and 6 match in that they both depict his mother's response: "she say, "mm $\mathrm{mm}$ / she didn't want me to tell her no Goldilocks story."

As Spencer shifted time frame and location into a new episode about Lynn on Gramma's porch, his narrative continued to reflect stanza structuring. Lines 9 through 12 all describe Lynn going somewhere, again in an aabb pattern. Lines 9 and 10 repeat the same structure "and Lynn went over. ...", and 11 and 12 follow a pattern of she + direction verb: "and she came/she was about to go back over..." Lines 13 through 18 also appear to form a stanza unit which focuses on the outcome of Lynn falling down on the porch.

We can see stanza patterning throughout the rest of Spencer's narrative as well. In Lines 21 through 24. Spencer produced a stanza that has an abab structure with Lines 21 and 23 expressing themes of obligation and responsibility: "I got a little baby cat . . . " and "I need to go find her." Lines 22 and 24 , on the other hand, begin with a description of the cats and in fact set the two cats in parallel contrast: "the baby cat is gone somewhere," "but the big cat just stay over my house." Later in his narrative, Lines 51 through 55 reflect an aabbb structure. Each of the lines in this stanza focus on name-calling. The first two lines follow the structure friend/relative + call me + name: "Rudy/John boy call me knucklehead/peanut," and the last three lines all end with the name "motor mouth."

In the last third of Spencer's narrative, we also see stanza structures in his anecdotes about turning different ages as well as in his fighting scenes. Lines 96 through 102 might be divided into two stanzas, three and four lines respectively, which more or less follow this structure: "I (think I) turned age." The following lines, 103 through 105, continue this theme of time landmarks in Spencer's life by describing changes he has made between grades in school. In these lines. Spencer describes the moving into and out of grades: "I was in pre-school/l got out of there/I came to kindergarten." In the following fighting sequence (Lines $110-135$ ), many of the lines display parallel grouping around the actions of "hitting" and "hitting back."

Stanza structuring can be seen in other episodes of Spencer's narrative that are not discussed in detail here. We hope that the examples above serve to illustrate some of the intricate internal patterning within Spencer's narrative that Gee also found to be characteristic of topic associating discourse. 
Structural devices can be seen in Spencer's narrative on a more global level as well. Gee (1991) has noted that, unlike topic centered stories, topic associating narratives achieve coherence, not through "rapid and linear progress to "the point," (p.11) but rather through the repetition of themes and contrasts (Gee, 1985 , p. 17). In the "Cakes" narrative that Gec $(1985,1986)$ analyzed, he found that the child repeated themes of baking and eating throughout the narrative (Gee, 1986, p. 401) and contrasted kinship relations with the outside world of commodities (Gee, 1991). These themes, says Gee, "run like strongly colored threads throughout the entire text" (1986, p. 401) and "give [it] an overall coherence and structure" (1985, p. 26).

Spencer's narrative reflects similar patterns of thematic repetition and coherence. First, Spencer repeated not only general themes, but entire episodes. For instance, the opening anecdote about Spencer trying to tell his mother the Goldilocks story is repeated again 61 clauses later in Lines 68 through 72. In both instances, Spencer began with a bedtime/sleeping context: "I was sleep" (Line 2 ); "when my mama was sleeping" (Line 68). He then described telling his mother the Goldilocks story which is followed by his mother's response (repeated nearly verbatim in the second anecdote) "she said, 'mm mm'." In both instances, Spencer then commented on a reason behind his mother's response. The first time he noted that "she didn't want me to tell her no Goldilocks story." In the second episode, Spencer described in more detail why his tired mother refused to listen to the Goldilocks story. He said, "and she was sleep/and the next day she had to go to work" (Lines 71--72). Just previously, Spencer had noted that his mon hates working at her job (Line 67), which he also repeated later in his narrative (Line 106).

Interestingly, Spencer began the second telling of the Goldilocks episode after he had become temporarily distracted with the interviewer and the microphone (Lines 56-65). It may be that the Goldilocks episode fills the opening slot in Spencer's narrative schema, the scene in which Spencer begins or re-begins his narrative. This repetition of placement suggests that Spencer's narrative follows a specific structural template. It is also interesting to note that the Goldilocks scene is followed immediately in both cases by an anecdote involving Lynn and Gramma, although in the second case it is only Spencer who goes over to Gramma's (Line 74), whereas in the first instance, it is both Lynn and Spencer (Lines 9-10; 19).

At the end of his narrative (Lines 142-157), Spencer also repeated a dream episode similar to one which he had narrated earlier in his story (Lines 78-90). Although the two dream sequences do not match as closely as the Goldilocks anecdotes, they nevertheless reflect some parallelism. They begin with a line "I be/was dreaming something." Also, in both cases, Spencer described the dreams as "bad" (Line 81) or "scary" (Line 153), and both involve a wolf (Lines 87-90, 157). The repetition of the dreaming anecdotes again suggests the importance of these sequences in the thematic development of his narrative. 
The overall structure of Spencer's narrative can be seen in the repetition of themes across different episodes as well. Many of the episodes in his narrative involve contrasts between interpersonal conflicts and resolutions. In both of the Goldilocks episodes, Spencer described his mother's negative response to his attempts to tell the Goldilocks story: "she say $\mathrm{mm} \mathrm{mm} / \mathrm{she}$ didn't want me to tell her no Goldilocks story." Her refusal presented a distancing conflict between Spencer and his mother. However, in both cases the scene of his mother's refusal is followed by another in which family caretaking is provided and not refused. After the first Goldilocks episode, Spencer narrated a seene in which Lynn fell down on the porch and got a bump on her head. Here, however, Spencer's mother is present to give comfort: "and now she laid in bed/my mama had to get her some ice" (Lines 17-18). After the second Goldilocks episode, it is Rudy and Gramma who provide caretaking for Spencer. Rudy came over to Spencer's house and picked him up "so I could go to bed over at Gramma's." (Lines 73-74) Thus, Spencer's narrative seems to resolve the themes of refusal and conflict in subsequent scenes of family and comfort. Interestingly, in Lines 37 and 38 . Spencer mentioned that he can read his book "all by myself/"cause my mamma just teach me how to read the jungle book. "This portrait of his mother reading to him dramatically contrasts with her refusal to hear the Goldilocks story. Thus. Spencer provided here another scene of caretaking which offers a potential resolution to the earlier conlict with his mother.

This contrast between conflict and comfort is seen also in the episode about Spencer and his cats (Lines 21-27). Here. Spencer said that the baby cat "is gone somewhere," suggesting again a removal of attention from Spencer. This was resolved, however, when Spencer revealed that not all the cats have left him. In contrast to the baby cat, "the big cat just stay over my house" (Line 24) and did not refuse Spencer's attention: "and 1 just pet him" (Line 26).

Beginning in Line 40, Spencer narrated another scene quite similar to the Goldilocks episode, in which he offered to give something which is refused by his kin. This time he asked Rudy and Gramma, "do you want some cornbread and stringbeans?" As he did with his mother, Spencer quoted Rudy and Gramma's refusal: "they said, "uh uh'." This scene led to another one involving namecalling between Spencer and his relatives/friends that again may reflect a distancing interpersonal conflict. However. Spencer does not provide a contrasting. comforting resolution to the dinner refusal or name-calling incidents, perhaps because this is the point when he gets distracted by the microphone.

Although the dream sequences in this narrative do not directly involve conflicts with family, they continue to reflect the contrasts between problems and resolutions. In the first dream episode, Spencer described the problem in his dream. He said that he was dreaming about something "bad" (Line 81 ) involving "digging," and "three little pigs and a wolf." The fears in his dream are resolved, however, when the wolf jumps into a bowl of water. Spencer said, "I was so happy/ cause I'm scared of wolf" (Lines 89-90). In the second dream sequence 
(Lines 142-157), Spencer is also dreaming about something scary: "something like monsters" (Line 142). As in the Goldilocks and cats episodes, Spencer again created a contrast between his conflicts and fears and the comfort found at home. Here, he repeated a cycle of going to bed, dreaming, and waking up. It is the waking up in his home environment that separates him from the fears of his dreams: "I dream a monster/and I was scared/and I woked up/and I was still keeping my eyes open" (Lines 152-155).

Spencer continued the themes of interpersonal conflicts and resolutions in his long fighting sequence (Lines 110-141). Here, Spencer repeated a cycle four times in which Louis (perhaps a classmate or neighbor) hits Spencer, a girl named Tanya intervenes on Spencer's behalf, and Spencer hits Louis back (Lines $110-116,117-122,123-127,128-133)$. In the last cycle, Spencer said that both he and Tanya hit Louis who this time cried: "and he cry hard, loud too/ . . . just like he was screaming loud" (Lines 135-136). Spencer connects Louis' screaming to another conflict involving the police. He says that Sheri told him that if you scream loud, "the police take you inside the jail" (Lines 137138). Spencer actually placed himself inside the jail: "so I see the jail/and you can't get out." Thus, he again found himself in a fearful, conflict situation. In his next line, however, Spencer shifted away from the fears of fighting and jail to the comforts of home and school represented by his ABC puzzle book (Line 141).

Spencer's multi-episodic narrative reflects a large degree of parallelism and thematic cohesion in both the internal structuring of his stanzas and the global schema of his story. The repetition of Spencer's conflicts and their resolutions suggests a contrastive framework through which he has created structure and meaning in this topic associating narrative.

\section{Frequency of Narrative Styles}

Because all of the narratives in the Pontiac data were produced by African American kindergartners, one might have expected, based on Michaels' observations of first-graders during sharing time, that this group of children would tend to adhere to a topic associating style. Indeed, one would especially expect the Pontiac kindergartners to display a topic associating style since they were one school year or more younger than Michaels' first graders and thus were much less developed in terms of their classroom narrative skills. However, as shown in Table 2, of the 48 narratives, there were 16 topic associating stories (33.3\%), 28 topic centered stories $(58.3 \%)$, and $4(8.3 \%)$ stories whose category membership was not clear enough to be assigned. Thus, more than half of the narratives followed a topic centered style, which Michaels had said was characteristic of Caucasian, but not African American first-graders' narratives during sharing time.

As shown in Table 2, we found that a number of these kindergarten-aged African American children $(n=16)$ used a topic associating style. This confirms that, within an uninterrupted storytelling task, the discourse style Michacls found 
TABLE 2

Frequency of Narrative Styles

\begin{tabular}{lcc}
\hline Narrative Styles & Frequency & Percentages \\
\hline Topic Centered & 28 & 58.3 \\
Topic Associating & 16 & 33.3 \\
Other & 4 & 8.3 \\
Total & 48 & $100 \%$ \\
\hline
\end{tabular}

* Figures have been rounded to nearest tenth so total may not equal exactly $100 \%$.

with the African American first-graders was also present for some of these children. Also, as our in depth analyses reveal, these topic associating stories, as shown in Example 2 (Spencer), contain complex structural and thematic devices, some of which Gee (1985, 1986, 1991) had found to be characteristic of literary texts. However, the topic associating style, although clearly present, was not predominant among this group of African American children. The majority of the kindergartners $(n=28$ ) did not demonstrate a topic associating style but rather tended to adhere to the patterns of topic centered discourse.

Because Michaels' study did not focus on the actual frequencies of topic centered and topic associating marratives but rather on characteristics of the styles and their roles in teacher-child interactions, it is difficult to create a systematic comparison between the findings of her study and this one. However, her study did suggest a general tendency for the $\Lambda$ frican $\Lambda$ merican first graders to tell topic associating narratives. We did in fact replicate her findings in that one third of our kindergartners told topic associating stories. Here we offer some possible explanations for the different discourse tendencies found in the remainder of the children in this study.

\section{Possible Effects of Contexts}

One reason why this group of children showed less of a tendency towards topic associating discourse than was suggested in Michaels' study may be due to differences in the two narrative contexts. Here we will consider the communicative situations as well as the tasks involved in the two narrative contexts. The activity of sharing time is a formalized type of dialogue in many classrooms. In Michaels' study, it was also conducted in a special setting-with the children sitting on the rug listening to one of their peers. Sharing time was also interactional; Michaels said that during a child's sharing turn, the teacher and other children often interjected with questions and comments (Michaels, 1981, 1986).

Michacls reported that in the classroom she studied, the sharing time task had some "ground rules" laid down by the teacher, such as talking about "one thing" or something that was "very important." She, as do we, interpreted the teacher"s communications as setting sanctions for the involvement of literacy-oriented 
standards to the children's speech: talk about one thing, decontextualize for your hearers, and interrogate the speaker to help him or her provide decontextualized information.

In contrast, the context presented to the Pontiac kindergartners involved faceto-face interaction which was designed to allow the children to tell a complete story without interruption. Indeed, in this way, it had the potential of increasing the likelihood that children would tell fully embellished, topic associating narratives. Although the task prompt, "tell a story" was expanded with two possible categories of content ("something fun or exciting that you've done or anything else you want to tell about"), no further ground rules were provided and no sanctions were established. Thus, if a child began to talk about a different topic, such as a familiar storybook, the adult simply accepted that story.

Within this uninterrupted situation in which the adult accepted all the productions of the child, the children generally produced the type of narrative suggested, a personal experience narrative. As shown in Table 3 , of the 28 topic centered stories, 17 were personal experience (both past and habitual) narratives, and of the 16 topic associating stories, 13 were personal experience narratives. In addition to these personal experience stories, however, some of the children told other types of narratives. For example, 9 of the topic centered narratives were retellings of familiar stories often found in storybooks. Also, 2 topic centered and 3 topic associating narratives were placed in a category called "other" because they could not be identified clearly as personal experience stories. These narratives often involved fantastical themes and characters, although it was not clear either that they were based on a single familiar storybook or fairy tale.

The lack of sanctions within the storytelling context may have encouraged some of the children to use narrative frameworks other than personal experience which helped contribute to a larger number of topic centered narratives. In both topic associating and topic centered narratives, we noticed intrusions of themes, content, and wording from children's storybooks and fairy tales (which may or may not have been learned from books). The influence of storybook themes and structure, however, was most pronounced in 9 of the 28 topic centered stories that retold familiar storybook narratives

TABLE 3

Frequency of Narrative Types

\begin{tabular}{lcc}
\hline \multicolumn{1}{c}{ Narrative Types } & Topic Centered & Topic Associating \\
\hline Pesonal Experience Narratives & 17 & 13 \\
Familiar Storybook Narratives & 9 & 0 \\
Other & 2 & 3 \\
Total & 28 & 16 \\
\hline
\end{tabular}


Within a context in which the adult was not interrupting or redirecting the child's narrative, the prompt "tell me a story" may have led these 9 children to use a certain schema of "story," one modeled after a storybook type of narrative. The teachers were doing some reading of storybooks to these children. There is also evidence that a number of the children were read to at home. Although the researchers did not mention storybooks, it is possible that the 9 who retold familiar storybook narratives may have given that interpretation when asked to "tell a story." This would imply that these children included "storybook" within their category system for "story." This storybook schema may have led these children to use a topic centered style which reflected the linear sequence and thematic cohesion of a book. Anthony's example illustrates a retelling of the "Goldilocks and The Three Bears" story.

\section{Example 3: (Anthony)}

1 once upon a time there was three little bears, the middle size bear, and the papa bear, and the small bear

2 and went out

3 and the Goldilocks ate up all their food

4 and tried everybody thing, and they bed, and they soup, and they chair, and they bed

5 and she finally got her a nice bed

6 that was the baby bed

Anthony's narrative reflects a topic centered style in that it follows a linear story grammar schema. Using Labov and Waletzky's (1967) model of narrative components, we see that Anthony's story contains an orientation section where he introduces the characters with the formulaic storybook opening "once upon a time there was three little bears." Moreover, although his story deviates somewhat from the usual plot structure, it nevertheless contains a complicating action centering around Goldilocks entering the bears' home and trying "cverybody thing," as well as a resolution coming at the end of the story when Goldilocks finally finds a nice bed to sleep in. Again, the fact that Anthony's story follows a linear organization and does not include any seemingly unrelated anecdotes gives it a topic centered appearance.

One might argue that familiar storybook retellings would be better categorized separately from both the topic centered and topic associating narratives because they are based at least in part on children's knowledge of the original story structure rather than on ways of structuring personal experiences. However, story retellings were included in the categorization because they were, in fact, narratives that were produced in response to the narrative task, which neither specified nor encouraged the retelling of a familiar literary narrative. Moreover, some of the children, like Anthony, deviated from the traditional story line. They also used their own style of language in their tellings so that their stories represent 
unique attempts to structure a narrative and are not just verbatim repetitions of stories they have heard before.

Note the presence of Anthony's own African American dialect in his narrative: the use of the third person plural pronoun "they" instead of the standard English possessive adjective "their" as well as the colloquial construction "got her a nice bed." Also, Anthony told the Goldilocks story from an original angle, leaving out the traditional scenes in which the bears return and find Goldilocks in their home. This narrative, therefore, appears to be Anthony's own version of the Goldilocks story.

Some of the children's metacommentary on their narratives further suggested that they saw the task as involving book-focused storytelling. One child, Nicole, began the task by telling the interviewer about a book that she has. She said, "I have a book. It's about a little engine." After Nicole narrated the contents of this book, she told about another book that she has: "I got a book about the kids at B-_- Street," and described some the characters from that one. At the end of her narrative, she said "that's all the stories I know," suggesting that to her, telling a story means to tell about familiar books.

Indeed, three children also responded to the storytelling task by singing familiar songs: "Three Little Monkeys," "Old McDonald Had a Farm," and "Jingle Bells." These children were not counted in the analysis because they did not produce real narratives. However, the fact that they responded to the task with a song suggests that they may have seen the task as one which required the retelling of a formal, previously composed work much like a storybook.

Perhaps the most striking example of one child's strictly "book-based" concept of "story" is found in Rashon's narrative. The transcript begins with a long preamble between Rashon and the interviewer.

\section{Example 4: (Rashon)}

Adult: Rashon, today I want you to tell me a story. The story can be about something fun or exciting that you've done or anything else you want to tell about. Tell me a story.

Child: I don't got none. And I ain't got no books.

Adult: Well, tell me a story. Tell me a story about something fun that you do at home or something fun that you do at school.

Child: We read stories at school.

Adult: Tell me a story.

Child: I don't know what's the name of them. But I don't know the words neither.

Adult: Well, you tell me a story. You tell me a story in your own way. It doesn't have to be a story from school. I want you to tell me a story.

Child: Can't guess.

Adult: Tell me a story about something fun you do with your family or something fun that you do with your friends.

Child: I can't guess nothing, shooooo. 
Adult: Well, think, just think for a minute. Your own story, tell me.

Child: Can't guess.

Adult: Tell me a story about something fun you do with your friends when you're outside.

Child: They don't have no books. Alls I got is Bibles.

Adult: Well, Rashon, the story doesn't have to be about a book. The story, it's your story. You tell me a story about something fun that you do with your friends inside when you're playing or outside when you're playing, or something fun that you do with your fanily, or a story about something scary that happened to you.

1 three billy goats

Adult: OK, tell me a story about three billygoats.

2 I can't guess what the man was named

3 they had a frog and a bat

4 yeah. he was a troll

5 two little billy goats and one big one

6 the baby went across the bridge first

7 the troll caught it and said, "who's that trippin" over his bridge"

8 and he said. "the billygoat"

9 and he said, he said he was gonna go up there to get some free grass

10 and then he said XX

11 the billygoat gobbled the little one up

12 and that's the end of the story

In his interaction with the interviewer, Rashon first began by insisting that he did not have a story or any books. He mentioned that they read stories in school, suggesting that he associated "story" with written storybooks. Even after the interviewer encouraged him several times by saying that the story does not have to be about a book but about something from Rashon's own life (about his family or about playing with friends), Rashon continued to assert that stories are not for making up, or constructing on one's own. He said he didn't know the name or words of any, and insisted several times that you "can't guess," implying that for him, stories are narratives which are already established, most likely in print. Indeed, he even mentions that the only stories/books he has "is Bibles."

In the end, Rashon did produce a storybook narrative about "the three billygoats" (a retelling of the familiar "The Three Billygoats Gruff") which reflected a quite literate, decontextualized style. One particularly notable element in his narrative is that he attempted to introduce or decontexualize each of the characters in the beginning of his story. He admits that he "can't guess what the man was named" (Line 2) but he introduces him with the indefinite article in Line 4 "he was a troll." He also gave some background information about the three billygoats - "two little billygoats and one big one." This type of explicit labeling of characters is a characteristic of a middle-class. "mainstream" narrative style 
(Heath, 1982) and is often only seen in older children's narratives (Peterson, 1990). Again, narratives such as Rashon's suggest that some of the children saw the task as one which required the telling of narratives modeled after the structure of books, which perhaps led to their topic centered style and contributed to the number of topic centered narratives.

In addition to the 9 children who told retold familiar storybook narratives, however, there were 17 children who told topic centered personal experience narratives. Here it would be difficult to claim that the prompt "tell a story" suggested a book-like narrative schema leading to a topic centered style, because these children were not in fact telling a story from a storybook.

However, within personal experience narratives in both topic centered and topic associating categories, we also often found storybook themes and language. The presence of such features further illustrates the variety of narrative discourse these children could produce within an uninterrupted context. A booklike style was reflected in one topic centered past experience narrative told by Ieshai.

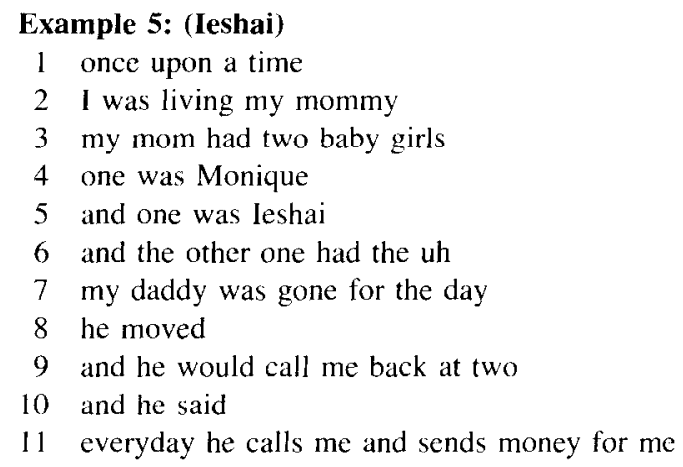

Like the other topic centered narratives, this narrative develops around a linear narrative event structure, although one can assume that there were significant time lapses between each event in the sequence. First, the main characters Monique and Ieshai - are introduced in the orientation (Lines 1-5). The orientation also serves as the first event in the narrative, where Monique and Ieshai are born into this world. Lines 7 and 8 can be seen as the story's complicating event since they describe the removal of the father from the lives of these two girls. Finally, the narrative ends with a resolution to this crisis where Ieshai described how, despite her father's moving away, she is still cared for by him as he calls her everyday and sends money for her (Lines 9-11).

Perhaps even more striking about this story, however, is leshai's use of the third person to refer to herself and her sister in Lines 3 and 6. This type of reference of the narrator towards him/herself has been described by Scollon and Scollon (1981) as "the fictionalization of self" and is said to be characteristic of 
literate-style narration. Scollon and Scollon argued that the removal of the first person voice of the author from the text is part of what characterizes a modern. Western style of essayist prose in which the author "seeks to achieve a state of self-effacement" and the text itself proposes to be the communicator of knowledge (pp. 48-49). As part of their study, they compared the narrative development of their 3-year-old daughter, Rachel, who they said came out of a literate narrative tradition, with the "oral" storytelling style of Athabaskan Indian children. One element they noted in Rachel's stories which was not present in the Athabaskan narratives was this reference to herself as a third person character. Of Rachel's reference to herself they remark:

The character in regard to the author is a different person. It is a decontextualized person. . . This person bears a third person relationship to the author, and this consistent maintenance of the point of view is one of the hallmarks of written text. (p. 70$)$

This same "fictionalization of self" was achieved by leshai as she referred to herself and her sister as the "two baby girls--Monique-and Ieshai."

Although topic associating stories were not dominated by storybook structure. they also alluded to books, and storics in books, or included episodes from them. For example, the three topic associating narratives in the eategory "other" conlained a number of fantastical themes and characters. such as Santa Claus. witches, and animated foxes and pumpkins, which may have been taken from storybooks or fairy tales. Some of the personal experience topic associating narratives also included references to books and storybook episodes. In Example 2. Spencer mentioned wanting to tell the Goldilocks story to his mother and thinking about saying "it all to my own self" (Line 7). He also refers to reading books by himself in lines 37 and 38: "and I could read my book all by myself/ cause my mamma teach me how to read the jungle book." Although Spencer's narrative reflects a global topic associating structure, it also includes lincarly presented episodes based on storybook themes. In Lines 84 through 90. Spencer dreamed that he was a pig in the "Three Little Pigs" story. This episode is told with treatment of self as fictional other ("I was dreaming about three little pigs and I was a pig") that extends through an episode which ends with a resolution ("I was so happy cause I'm scared of wolf").

\section{CONCLUSION}

In sum, this study partially replicated Michacls' observations of African American first-graders in sharing time in that a number of these kindergartners did in fact produce topic associating narratives. Indeed, in the personal experience narratives, the numbers of topic centered $(n=17)$ and topic associating $(n=13)$ stories were reasonably close. However. among this group of children. the topic 
associating style was not predominant. In fact when we consider all of the narratives produced, the majority of the kindergartners $(n=28)$ told topic centered narratives. The storytelling context may be one reason why the children in the Pontiac study followed a topic centered model of discourse more often than has been suggested in previous research (Michaels, 1981, 1986). The lack of sanctions presented in the uninterrupted storytelling context may have led to the use of a range of narrative frameworks. This openness to frameworks, as well as the task prompt "tell a story," may have led some of the kindergartners to produce narratives that included structural and stylistic elements of books. This pattern seems to be reflected most clearly in the 9 children who retold familiar storybook narratives. In the cases of the 17 topic centered personal experience narratives, it is difficult to claim that a "storybook" task effect led to their topic centered style. However, the storybook themes and language found across different types of narratives in both topic centered and topic associating categories further illuminate the variety of narrative discourse that these children were capable of producing within an uninterrupted context.

Michaels' work with first-graders' sharing time narratives was key in helping to describe particular patterns of discourse organization found in our sample of African American kindergartners' narratives. Her analyses, as well as Gee's narrative descriptions, have contributed useful classification systems for categorizing such narratives and illuminating the ways in which discourse styles may affect teacher-student interactions. This study has attempted to address a question left open by Michaels' research by examining the frequency of topic associating discourse in another group of African American children and in a context other than sharing time. Indeed, we found that topic associating stories existed within the discourse repertoires of this new population. However, the fact that the children from the Pontiac study produced more topic centered than topic associating narratives suggests that, as has often been pointed out, African American children are not restricted to a predominant narrative style. We also concur that, as Michaels and Gee have observed, literate characteristics can be found in both topic centered and topic associating styles.

A further study continues to address the question of discourse style frequency by examining variation and stability of topic centered and topic associating discourse in these children's performances across oral and written contexts (Dorfman, 1993). Also, preliminary analysis from another project (unpublished raw data from the studies reported in Sulzby \& Teale, 1984, 1987) suggests that young children from European-American Appalachian backgrounds as well as African American backgrounds may tell what appear to be topic associating stories in storybook reading or writing sessions.

Although the performance of the children in the Pontiac study serves to extend current knowledge of language variation and enrich our understanding of the nature of topic centered and topic associating discourse styles, it also urges us to consider classroom contexts for children's use of language. During the year 
following these initial stories, these kindergarten children's teachers shifted instructional practices. In three classrooms, children were encouraged, in varying degrees, to read and write emergently and to move from center to center for choices of activities. In all four classrooms, computers were provided with software designed to support emergent literacy. University staff helped in the classrooms from 1 to 2 days per week. Children were allowed to speak much more freely and took more initiative in speech with the teachers, university staff, and each other. Still, there were few opportunities in which children could maintain an audience for a narrative as long as that of Spencer or other children using a topic associating style. There were also relatively few times for children to share any long oral or written stories. The challenge for teachers over the subsequent three years of this study has been to provide appropriate audience situations that encourage children to use the full range of their speaking and writing capabilities. The possibilities that exist require teachers to allow children to speak often and to speak freely in dyads or small groups and to set up facilitative classroom management routines to help children use such freedom. For now, the study presented here provides evidence of how children tell extended narratives in contexts not yet available in these classrooms.

\section{REFERENCES}

Abrahams, R.D. (1970). Traditions of eloquence in the West Indies. Journal of Inter-American Studies and World Affairs, 12,505-527

Abrahams, R.D. (1972). The training of the man-of-words in talking sweet. Language in Societs. I, 15-29.

Applebee, A.N. (1978). The child's concept of story: Chicago: The University of Chicago Press.

Christie, F. (1991). Genres as social processes. Working with Genre: Papers from 1989 LERN Conference, University of Techology, Sudnev (pp. 73-88). Sydney. Australia: Common Ground.

Dorfman. A. (1993). African-American LSES kindergarmers' marrative styles across oral and witten tasks. Unpublished manuscript, The Lniversity of Michigan. Combined Program in Education and Psychology, Ann Arbor, MI.

Ferguson, C.A. (1982). Simplified registers and linguistic theory. In L.K. Obler \& L. Menn (Eds.). Exceptional language and linguistics (pp. 49-66). Now York: Academic.

Gee, J.P. (1985), The narrativization of experience in the oral style. Journal of Edacation. 167. 9. 36.

Gee. J.P. (1986). Units in the production of narrative discourse. Discourse Processes, 9. 391-422.

Gee, J.P. (1991). Memory and myth: A perspective on narrative. In A. McCabe \& C. Peterson (Eds.), Developing murrative structures (pp. 1-25). Hilldale. NJ: Erlbaum.

Halliday. M.A.K.. McIntosh. A.. \& Strevens, P. (1964). The linguistic scicnces and language reaching. London: Longman.

Haviland, J.B. (1979). Guugu yimidhirr brother-in-law language. Lamguage and societs, 8, 365--39.3.

Heath. S. B. (1982). What no bedtime story means: Narrative skills at home and at school. Language and Societs, $11,49-76$.

Hicks. D. (1991). Kinds of narrative: Genre skills among first graders from two communities. In A. MeCabe \& C. Peterson (Eds.). Develeping narrative structures (pp. 55-87). Hilldale. NJ: Erlbaum. 
Hudson, J., \& Shapiro, L. (1991). From knowing to telling: The development of children's scripts, stories and personal narratives. In A. McCabc \& C. Peterson (Eds.), Developing narrative structures (pp. 89-136). Hilldale, NJ: Erlbaum.

Labov, W., Cohen, P., Robins, C., \& Lewis, J. (1968). A study of the non-standard English of Negro and Puerto Rican speakers in New York City. New York: Columbia University Press.

Labov, W., \& Waletzky, J. (1967). Narrative analysis: Oral versions of personal experience. In J. Helm (Ed.), Essays on the verbal and visual arts (pp. 12-44). Seattle: University of Washington Press.

McCabe, A., Capron, E., \& Peterson, C. (1991). The voice of experience: The recall of early childhood and adolescent memories by young adults. In A. McCabe \& C. Peterson (Eds.). Developing narrative structures (pp. 137-173). Hilldale, NJ: Erlbaum.

Menig-Peterson, C.L., \& McCabe, A. (1978). Children's orientation of a listener to the context of their narratives. Developmental Psychology, 14, 582-592.

Michaels, S. (1981). Sharing time: Children's narrative styles and differential access to literacy. Language and Society, 10, 423-442.

Michaels, S. (1986). Narrative presentations: An oral preparation for literacy with first graders. In J. Cook-Gumperz (Ed.), The social construction of literacy (pp. 94-116). Cambridge: Cambridge University Press.

Michaels, S. (1991). The dismantling of narrative. In A. McCabe \& C. Peterson (Eds.), Developing narrative structures (pp. 303-351). Hilldale, NJ: Erlbaum.

Michaels, S., \& Cazden, C.B. (1986). Teacher/child collaboration as oral preparation for literacy. In B.B. Schiefflin \& P. Gilmore (Eds.), The acquisition of literacy: Ethnographic perspectives (pp. 132-154). Norwood, NJ: Ablex.

Peterson, C. (1990). The who, when, and where of early narratives. Journal of Child Language. 17, $433-455$.

Peterson, C., \& McCabe, A. (1983). Developmental psycholinguistics: Three ways of looking at a child's narrative. New York: Plenum.

Prince, E. F., Frader, J., \& Bosk, C. (1982). On hedging in physician-physician discourse. In R.J. Di Pietro (Ed.), Linguistics and the professions (pp. 83-97). Norwood, NJ: Ablex.

Reid, T.B.W. (1956). Linguistics, structuralism and philology. Archivum Linguisticum, 8, 28-37.

Rochester, S., \& Martin, R.R. (1979). Crazy talk: A study of the discourse of schizophrenic speakers. New York: Plenum.

Scollon, R., \& Scollon, S. (1981). Narrative, literacy, and face in interethnic communication. Norwood, NJ: Ablex.

Selinker, L., \& Douglas, D. (1989). Research methodology in contextually-based second language research. Second Language Research, 5, 93-126.

Shatz, M., \& Gelman, R. (1973). The development of communication skills: Modifications in the speech of young children as a function of listener. Monographs of the Society for Research in Child Development, 38, 1-37.

Shatz, M., \& Gelnian, R. (1977). Beyond syntax: The influence of conversational constraints on speech modifications. In C. Snow \& C. Ferguson (Eds.), Talking to children: Language input and acquisition (pp. 189-198). Cambridge: Cambridge University Press.

Stein, N.L., \& Glenn, C.G. (1979). An analysis of story comprehension in elementary school children. In R.O. Freedle (Ed.), New directions in discourse processing (pp. 53-120). Norwood, NJ: Ablex.

Sulzby, E. (1985). Kindergartners as writers and readers. In M. Farr (Ed.), Advances in writing research: Vol. 1. Children's early writing development (pp. 127-199). Norwood, NJ: Ablex.

Sulzby, E. (1990, December). Computers as evolving literacy tools: A first-year report of Project CIEL. Paper presented at the annual meeting of the National Reading Conference, Miami.

Sulzby, E., Branz, C.M., \& Buhle, R. (1993). Repeated readings of literature and LSES black kindergartners and first graders. Reading and Writing Quarterly, 9, 183-196. 
Sulzby, E., \& Kamberelis, G. (1990, April). The effects of dialect differences in andlyzing the

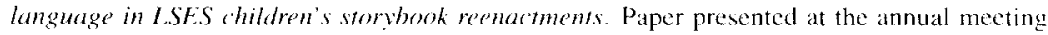
of the American Educational Rescarch Association. Boston.

Sulbby, E., \& Teale, W.H. (1984). Young children's sorvbook reading: Hispanic and Anglo families and children, interim repont to the Spencer Foundation. Unpublished manuscript, The University of Michigan, Ann Arbor.

Sulzby.E.. \& Teale, W. H. (1987). Young children's sorvbot reading: Longindinal sudy of parent child interaction and children's independent functioning, find report to the Spencer Foundation. Unpublished manuscript, The Lniversity of Michigan, Ann Arbor.

Swales, J.M. (1990). Genre analysis. Cambridge: Cambridge University Press.

Tannen, D. (1982). The oral/literate eontinuum in discourse. In D. Tannen (Ed.), Spoken and written language: Exploring orality and literacy (pp. 1-16). Norwood, NJ: Ablex.

Vygotsky, L.S. (1962). Thought and language. Cambridge. MA: MIT Press. 